De la exceptional capacidad del señor Umbricht como mediador e intermediario internacional se beneficiaron tanto el Movimiento de la Cruz Roja y su objetivo específico de ayuda y protección a las víctimas de las guerras como los millones de hombres y mujeres en cuyo favor intervino infatigablemente en el mundo entero.

Al rendir homenaje a la memoria del señor Victor H. Umbricht, el presidente del CICR, señor Cornelio Sommaruga, declaró: «Victor Umbrecht se consagró a la causa de la Cruz Roja con un optimismo inquebrantable, una inconmovible energía y una abnegación infatigable... Victor Umbricht, verdadero ciudadano del mundo, no se contentó con ser un simple miembro; se identificó totalmente con los objetivos del CICR y quiso también que nuestra Institución se mantuviera fiel a sus principios de competencia absoluta, de no-formalismo, de discreta modestia y de tolerancia sin paternalismo... Sus objetivos y anhelos siguen siendo los nuestros. Le estamos profundamente agradecidos por habernos servido de ejemplo,... y estamos impregnados de su modelo».

\title{
Fallecimiento del profesor D. Frei, miembro del CICR
}

El profesor Daniel Frei, miembro del Comité Internacional de la Cruz Roja desde el 1 de marzo de 1986, falleció repentinamente el 1 de agosto de 1988.

Nacido el 24 de octubre de 1940 en San Gall, Daniel Frei era doctor en Historia por la Universidad de Zurich a los 24 años. Prosiguió sus estudios en la «London School of Economics and Political Science», y después en la Universidad de Michigan y, en 1967, se diplomó en el Instituto Universitario de Altos Estudios Internacionales de Ginebra.

En 1968, fue nombrado profesor asociado y, en 1971, profesor ordinario de Ciencias Políticas en la Universidad de Zurich, donde también dirigió el Instituto Suizo de Investigaciones Internacionales.

Daniel Frei es autor de numerosas publicaciones sobre las relaciones este-oeste, el desarme, la neutralidad y la cooperación internacional. Era miembro del Club de Roma y asesor del UNITAR (Instituto de las Naciones Unidas para la Formación Profesional y la Investigación) 
y del UNIDIR (Instituto de las Naciones Unidas de Investigación sobre el Desarme).

Desde que fue designado miembro del Comité Internacional de la Cruz Roja, puso su amplio saber al servicio del Movimiento Internacional de la Cruz Roja y de la Media Luna Roja y se entregó con convicción a nuestra causa.

Formó parte de varias comisiones del CICR, como las de doctrina, de política general y de relaciones con los otros componentes del Movimiento, así como de los Grupos de Trabajo «Avenir» y de Relaciones Públicas, además del Fondo Clara Benedict. Fue miembro de la Comisión de la Cruz Roja, la Media Luna Roja y la Paz, así como del Grupo de Expertos sobre los derechos humanos, designado por esa Comisión. El señor Frei iba a ser nombrado miembro de la Asamblea General del Instituto Henry Dunant. También formó parte de la delegación del CICR en la XXV Conferencia Internacional de la Cruz Roja en 1986. Efectuó varias misiones para el CICR en Turquía, Jordania, Rumania, Polonia, Guayana Francesa, Brasil, Estados Unidos, Bulgaria, Italia e Israel.

El Comité, conmovido por tan prematura partida, agradece profundamente su abnegación. 